\title{
Maps, Figures and Tables
}

Map of international shipments $\quad 17$

$\begin{array}{ll}\text { Map showing distribution of Elixir wholesales by county } & 19\end{array}$

Table 1: Annual Balances, 1674-1684 15

Table 2: Anthony Daffy's trade beyond England 17

Pages 3A and 3B of the manuscript Account Book showing details of Mrs Elizabeth Ainsworth's account (National Archives, Chancery: Unknown Masters' Exhibits, C 114/59) 